\title{
Avaliação da eficiência de extração de compostos nitrogenados da polpa de anchoíta (Engraulis anchoita)
}

\author{
Evaluation of the efficiency of nitrogen compounds extraction from the anchovy (Engraulis anchoita) pulp
}

Valcenir Júnior Mendes FURLAN ${ }^{1 *}$, Ana Paula Rosa da SILVA ${ }^{1}$, Maria Isabel QUEIROZ ${ }^{1}$

\section{Resumo}

Este trabalho teve como objetivo avaliar a eficiência da extração de compostos nitrogenados, como proteínas solúveis (PS), nitrogênio total (NT), nitrogênio não proteico (NNP) e nitrogênio proteico (NP) da polpa de anchoíta (Engraulis anchoita), bem como obter informações a respeito de sua composição proximal e do frescor em relação ao seu local de captura. A polpa de anchoíta foi submetida a tratamento de extração de nitrogenados utilizando como soluções $\mathrm{NaHCO}_{3}(0,1 ; 0,2 ; 0,3$ e 0,5\%), $\mathrm{NaCl} 0,3 \%$ e água destilada. O ciclo de lavagem da polpa utilizando $0,1 \%$ de $\mathrm{NaHCO}_{3}$, dois ciclos de água destilada e um ciclo de $\mathrm{NaCl} 0,3 \%$ demonstrou maior eficiência na extração dos compostos nitrogenados, assim como das proteínas sarcoplasmáticas. Na determinação da composição proximal, a anchoíta in natura apresentou valores de umidade de $77,2 \%$, proteína $16,8 \%$, lipídios 3,4\% e cinzas $2,4 \%$ e, para a polpa de anchoíta, foram encontrados valores de umidade de $78,1 \%$, proteína $17,5 \%$, lipídios $2,4 \%$ e cinzas $2,0 \%$. A avaliação do frescor foi determinada através do $\mathrm{pH}$, bases voláteis totais (N-BVT) e trimetilamina (N-TMA), encontrando-se valores de 6,$3 ; 11,5 \mathrm{mg} .100 \mathrm{~g}^{-1}$ e 2,8 mg.100 g $\mathrm{g}^{-1}$ para a anchoíta in natura e 6,7; 20,2 mg.100 g $\mathrm{g}^{-1} ; 3,1 \mathrm{mg} .100 \mathrm{~g}^{-1}$ para a polpa, respectivamente.

Palavras-chave: compostos nitrogenados; composição proximal; frescor; pescado.

\begin{abstract}
The objective of this work was to evaluate the efficiency of the nitrogen compounds extraction like soluble proteins (SP), total nitrogen (TN), non protein nitrogen (NPN), and nitrogen protein (NP) from the anchovy pulp (Engraulis anchoita), as well to investigate their proximal composition and freshness alteration based on the capture place. The anchovy pulp was submitted to nitrogen extraction treatment using $\mathrm{NaHCO} 3(0.1 ; 0.2 ; 0.3$ and $0.5 \%), \mathrm{NaCl} 0.3 \%$ as solutions and distilled water. The pulp washing cycles using $0.1 \% \mathrm{NaHCO}$, two cycles of distilled water, and one of $\mathrm{NaCl} 0.3 \%$ demonstrated improved efficiency in the extraction of the nitrogenous compounds and sarcoplasmatic proteins. Concerning the determination of the proximal composition, the anchovy in natura showed moisture content $77.2 \%$, protein $16.8 \%$, lipids $3.4 \%$, and ash $2.4 \%$ and the values for the anchovy pulp were moisture $78.1 \%$, protein $17.5 \%$, lipids $2.4 \%$ and ash $2 \%$. The freshness evaluation was accomplished through $\mathrm{pH}$, total volatile bases (N-BVT), and trimethylamine (N-TMA) and they were found $6.3 ; 11.5 \mathrm{mg} .100 \mathrm{~g}^{-1}$ and $2.8 \mathrm{mg} .100 \mathrm{~g}^{-1}$ for the anchovy in natura and $6.7 ; 20.2 \mathrm{mg} .100 \mathrm{~g}^{-1} ; 3.1 \mathrm{mg}^{100 \mathrm{~g}^{-1}}$ for the pulp, respectively.
\end{abstract}

Keywords: fish; freshness; nitrogen compounds; proximal composition.

\section{Introdução}

O pescado é importante fonte de componentes com significativo valor nutricional como proteínas e minerais (MAIA et al., 1999; OGAWA; MAIA, 1999), além de ser a maior reserva de ácidos graxos poli-insaturados, especialmente os da série ômega-3, aos quais são atribuídos numerosos benefícios ao organismo humano (LUZIA et al., 2003; TRONDSEN et al., 2003).

A proteína de origem animal mais consumida mundialmente é a do pescado, porém o Brasil apresenta baixos índices de consumo (PARMIGIANI; TORRES, 2005), os quais são atribuídos a fatores culturais, econômicos, à subutilização do produto da pesca e à falta de diversificação da indústria processadora de pescado (GARCIA, 2007).
Grande parte da captura mundial de pescado é proveniente de espécies marinhas, a metade correspondente a espécies demersais e o restante a espécies pelágicas (FAO, 1997). Entre os peixes pelágicos pouco explorados, destaca-se a espécie Engraulis anchoita (anchoíta), pertencente à família Engraulidae, do gênero Engraulis (GOULAS; KONTOMINAS, 2005; SCHWINGEL; CASTELLO, 2000). São pequenos peixes que possuem hábitos costeiros, amplamente distribuídos, desde o Golfo de São Jorge na Argentina até o Rio de Janeiro, mais especificamente no Brasil, entre Cabo Frio (RJ) e o Chuí (RS) (CASTELLO; CASTELLO, 2003).

No Atlântico Sul Ocidental, tem sido estimada a abundância da espécie Engraulis anchoita em diferentes épocas do ano e com

Recebido para publicação em 23/1/2008

Aceito para publicação em 3/1/2009 (003169)

Departamento de Química, Fundação Universidade Federal do Rio Grande - FURG, Campus Cidade, Pavilhão VII, $2^{\circ}$ Andar - Sala 723, Rua Eng. Alfredo Huch, 475,

CP 474, CEP 96201-900, Rio Grande - RS, Brasil, E-mail: juniorfurlan@yahoo.com.br

${ }^{*}$ A quem a correspondência deve ser enviada 
diferentes metodologias, sendo sugerido um valor em torno de 4 milhões de toneladas para a área total entre as latitudes de 34 e $47^{\circ} \mathrm{S}$, demonstrando o grande potencial econômico do recurso. Segundo Madureira et al. (2007), para a costa sul brasileira, estimou-se em 1.900 mil toneladas o estoque de Engraulis anchoita nos meses de inverno. Para a costa sudeste, a estimativa foi de 399 mil toneladas nos meses de outubro e novembro.

A anchoíta é uma espécie pouco explorada pela pesca comercial ou artesanal. Além disso, não existem impedimentos legais ou ecológicos que inviabilizem o início de uma atividade de pesca sobre este recurso (CASTELLO, 1997; MADUREIRA et al., 2007). Um dos motivos pelo qual esta matéria-prima é descartada ou processada como produto de baixo valor comercial, deve-se especialmente por ser um pescado de carne escura, suscetível à oxidação e sabor residual (THIANSILAKUL; BENJAKUL; SHAHIDI, 2007). Esses fatores decorrem em função do alto conteúdo de lipídios, proteínas solúveis, bem como pigmentos e óxido de trimetilamina.

Para viabilizar o aproveitamento da anchoíta na alimentação humana, neste trabalho foi realizado um estudo de lavagens na polpa desta espécie, com o objetivo de remover compostos nitrogenados, os quais são responsáveis pelo odor do pescado e aceleração da desnaturação proteica, a fim de se obter um produto rico em proteínas e aminoácidos essenciais, que poderá servir como base para o desenvolvimento de novos produtos, oferecendo à indústria uma alternativa para o aproveitamento desse recurso.

\section{Material e métodos}

\subsection{Captura da matéria-prima e armazenamento a bordo}

Os experimentos foram realizados com a matéria-prima resultante de dois cruzeiros realizados pelo Navio Oceanográfico Atlântico Sul da Fundação Universidade Federal do Rio Grande (FURG), RS-Brasil. A matéria-prima utilizada foi a anchoíta (Engraulis anchoita), com tamanho médio de $11,5 \mathrm{~cm}$ e $8 \mathrm{~g}$, capturada na costa do Rio Grande do Sul próximo à divisa Brasil-Uruguai. Logo após a captura, o pescado foi armazenado a bordo e imerso em gelo e água do mar (1:1) em caixas de polietileno, conforme descrito por Garcia (2007).

\subsection{Procedimento em terra}

Após o desembarque, a matéria-prima foi transportada para uma indústria pesqueira do complexo industrial da cidade de Rio Grande, onde foi lavada com água clorada em tambor rotativo, eviscerada e então transportada para o Laboratório de Análise Sensorial e Controle de Qualidade (LASCQ) da FURG em espaço de tempo inferior a 24 horas, onde foi armazenada sob congelamento $\left(-18^{\circ} \mathrm{C}\right)$.

Para a obtenção da polpa, o pescado foi lavado com água clorada em tambor rotativo e eviscerado, procedendo-se à separação mecânica e acrescentando-se 2,5\% de sacarose como crioprotetor. Posteriormente, foi transportado para o LASCQ da FURG, em espaço de tempo inferior a 24 horas, onde foi armazenado sob congelamento $\left(-18^{\circ} \mathrm{C}\right)$.

\subsection{Caracterização da matéria-prima}

\section{Composição proximal}

O pescado inteiro (in natura) e a polpa de pescado tiveram sua composição proximal determinada de acordo com a metodologia oficial (AOAC, 2000).

\section{Avaliação do frescor}

O frescor da anchoíta in natura e da sua polpa foi avaliado através do $\mathrm{pH}$, bases voláteis totais (N-BVT), segundo a metodologia indicada por Brasil (1981) e trimetilamina (N-TMA), segundo AOAC (2000). Para a determinação do N-TMA, a uma alíquota da amostra obtida por precipitação das proteínas com ácido tricloroacético foram adicionados formaldeído, tolueno e solução de hidróxido de potássio e, em seguida, agitada vigorosamente. Da camada de tolueno formada, pipetaram-se $5 \mathrm{~mL}$ de solução para um tubo contendo sulfato de sódio anidro, submetido à agitação. A esta mistura foi adicionada solução de ácido pícrico, que foi novamente agitada. Transcorrido o tempo para a reação colorimétrica, a solução foi lida em espectrofotômetro a $410 \mathrm{~nm}$. O resultado foi expresso em mg de N-TMA por $100 \mathrm{~g}$ de amostra a partir de uma curva padrão de TMA.

\section{Lavagem da polpa de pescado}

As lavagens da polpa de pescado foram realizadas nas seguintes condições: quatro ciclos de lavagens, empregando inicialmente solução de bicarbonato de sódio $\left(\mathrm{NaHCO}_{3}\right)$, água e solução de $\mathrm{NaCl}$ 0,3\%; na proporção 1:3 (p/v); período de extração total de 6 minutos; regime de agitação constante e temperatura entre 5 e $7{ }^{\circ} \mathrm{C}$. Os quatro ciclos de lavagens estudados estão apresentados na Tabela 1.

Na primeira lavagem utilizou-se como solução o $\mathrm{NaHCO}_{3}$, variando sua concentração em 0,$1 ; 0,2 ; 0,3 ;$ e $0,5 \%$ para os ciclos A, B, C e D, respectivamente. A segunda e terceira lavagens foram realizadas com água destilada e a quarta lavagem, com $\mathrm{NaCl}$ 0,3\% nos quatros ciclos.

Ao final de cada lavagem foi realizada a separação de sólidos por peneiramento manual utilizando-se uma peneira Tyler 200 e abertura de $0,074 \mathrm{~mm}$, conforme indicado por Simões et al. (2004).

Tabela 1. Ciclos de lavagens da polpa de anchoíta.

\begin{tabular}{ccccc}
\hline \multirow{2}{*}{ Ciclos } & \multicolumn{4}{c}{ Lavagens } \\
\cline { 2 - 5 } & $1^{\circ}$ lavagem & $2^{\circ}$ lavagem & $3^{\circ}$ lavagem & $4^{\circ}$ lavagem \\
\hline A & $\mathrm{NaHCO}_{3} 0,1 \%$ & $\mathrm{H}_{2} \mathrm{O}$ destilada & $\mathrm{H}_{2} \mathrm{O}$ destilada & $\mathrm{NaCl} 0,3 \%$ \\
B & $\mathrm{NaHCO}_{3} 0,2 \%$ & $\mathrm{H}_{2} \mathrm{O}$ destilada & $\mathrm{H}_{2} \mathrm{O}$ destilada & $\mathrm{NaCl} 0,3 \%$ \\
$\mathrm{C}$ & $\mathrm{NaHCO}_{3} 0,3 \%$ & $\mathrm{H}_{2} \mathrm{O}$ destilada & $\mathrm{H}_{2} \mathrm{O}$ destilada & $\mathrm{NaCl} 0,3 \%$ \\
D & $\mathrm{NaHCO}_{3} 0,5 \%$ & $\mathrm{H}_{2} \mathrm{O}$ destilada & $\mathrm{H}_{2} \mathrm{O}$ destilada & $\mathrm{NaCl} 0,3 \%$ \\
\hline
\end{tabular}




\section{Extração de compostos solúveis}

Nas soluções de lavagem resultantes da separação por peneiramento, foram determinados nitrogênio total (NT), nitrogênio não proteico (NNP), nitrogênio proteico (NP) e proteínas solúveis (PS). O NT foi determinado pelo método de Kjeldahl; o NNP, após precipitação das proteínas, com TCA 20\%; o NP por diferença entre o NT e o NNP; e as PS foram avaliadas pelo método de Biureto, utilizando-se uma curva de referência com albumina de soro bovino (BSA) com 95\% de pureza (MARTELLI; PANEK, 1968).

\section{Resultados e discussão}

\subsection{Caracterização da matéria-prima}

O conhecimento da composição da matéria-prima é de fundamental importância na aplicação de diferentes processos tecnológicos, além de influenciar no aspecto de qualidade geral, bem como nos atributos sensoriais e na estabilidade do armazenamento do produto final (GARCIA, 2007; OGAWA; MAIA, 1999; ORDÓÑEZ, 2005; YEANNES; ALMANDOS, 2003).

A Tabela 2 apresenta os resultados experimentais da composição proximal da anchoíta in natura e da polpa.

Observa-se que os valores encontrados para a composição proximal da matéria-prima in natura diferem da literatura, na qual Mattos et al. (1977) encontraram valores para umidade, proteína, lipídios e cinzas de 72,2; 16,9; 6,9 e 3,5\%, respectivamente. A anchoíta é considerada uma espécie gorda, no entanto, de acordo com Yeannes e Almandos (2003), a composição varia com os tecidos, sexo, idade do pescado e estação do ano, o que pode explicar as diferenças na literatura para esta espécie.

Os valores relacionados com a composição química da anchoíta mostram uma significativa divergência causada por uma nítida variação estacional. Bertolotti e Manca (1986) reportam que os valores médios de proteínas encontram-se entre 16,1 e $17,9 \%$, intervalo esse que contempla o resultado obtido neste trabalho.

Fuselli, Casales e Yeannes (1994) estudaram a composição da anchoíta (Engraulis anchoita) capturada no Rio da Prata (latitude $35^{\circ}-36^{\circ}$ ) e verificaram que esta espécie apresenta variações no teor de lipídios e umidade conforme a época de

Tabela 2. Composição proximal da matéria-prima e da polpa de anchoíta.

\begin{tabular}{ccc}
\hline $\begin{array}{c}\text { Componentes } \\
\left(\mathrm{g} .100 \mathrm{~g}^{-1}\right)\end{array}$ & $\begin{array}{c}\text { Matéria-prima in natura } \\
\text { experimental }\end{array}$ & $\begin{array}{c}\text { Matéria-prima polpa } \\
{ }^{*} \text { experimental }\end{array}$ \\
\hline Umidade & $77,2 \pm 0,28^{\mathrm{a}}$ & $78,1 \pm 0,37^{\mathrm{b}}$ \\
Proteína & $16,8 \pm 0,31^{\mathrm{a}}$ & $17,5 \pm 0,20^{\mathrm{b}}$ \\
Lipídios & $3,4 \pm 0,16^{\mathrm{a}}$ & $2,4 \pm 0,13^{\mathrm{b}}$ \\
Cinzas & $2,4 \pm 0,37^{\mathrm{a}}$ & $2,0 \pm 0,19^{\mathrm{b}}$ \\
\hline
\end{tabular}

* $(\mu \pm \sigma)=$ valores médios de 6 repetições \pm desvio padrão; $\mathrm{p} \leq 0,05$; letras iguais na mesma linha, não existe diferença significativa; letras diferentes na mesma linha, existe diferença significativa. captura. Os teores de lipídios e umidade encontrados pelos autores foram de 6,79 e 71,0\%, para o mês de junho, e de 3,93 e 75,7\%, para o mês de setembro, respectivamente. Os valores de lipídios e umidade para a matéria-prima in natura apresentados na Tabela 2 estão de acordo com Fuselli, Casales e Yeannes (1994), pois a anchoíta analisada neste estudo foi capturada entre os meses de agosto e setembro. Segundo Bressan (2002), de acordo com o teor de gordura, os peixes podem ser classificados em gordos ( $>8,0 \%$ de gordura), semigordos (3,0-8,0\%) e magros (2,0-3,0\%). Com isso, a espécie em estudo pode ser classificada como um pescado semigordo.

No estudo de Garcia (2007), o autor verificou que a anchoíta capturada na mesma região do presente trabalho apresentou um conteúdo para umidade, proteína, lipídios e cinzas de 77,9; 16,$4 ; 3,6$ e 2,0\%, respectivamente, estando de acordo com os resultados apresentados neste estudo.

O conteúdo de lipídios e de cinzas da anchoíta in natura apresentou uma diminuição significativa $(\alpha=5 \%)$ em relação à sua polpa. Do contrário, o conteúdo de umidade e proteína aumentou significativamente $(\alpha=5 \%)$, comparado com a polpa. Isso pode ser justificado pelo processo de separação mecânica, ao qual foi submetida a matéria-prima. Os resultados do frescor da matéria-prima in natura e da polpa podem ser observados na Tabela 3.

$\mathrm{O}$ pH é um parâmetro que indica a qualidade do alimento, pois é afetado por reações que ocorrem após a morte do animal, e indica a presença de microrganismos que através de seu metabolismo causam o acúmulo de material metabólico alcalino, elevando o valor do $\mathrm{pH}$ e diminuindo a qualidade do produto (MARTIN, 1982). Não foi verificada diferença significativa $(\alpha=5 \%)$ entre os valores de $\mathrm{pH}$ do pescado in natura $(6,3)$ e da polpa de anchoíta $(6,7)$. Neste sentido os resultados indicam o bom estado de conservação, considerando-se que os valores de pH não ultrapassaram o indicado pela legislação brasileira, que propõe um máximo de 6,8. O mesmo ocorreu para o N-BVT, cujos valores encontrados para o pescado in natura e para a polpa foram de 11,5 e 20,2 mg. $100 \mathrm{~g}^{-1}$, respectivamente, visto que o valor máximo para a comercialização, segundo a legislação, é de $30 \mathrm{mg} .100 \mathrm{~g}^{-1}$ de músculo (BRASIL, 1981).

Yeannes, Valle e Lupín (1983) reportam que as anchoítas provenientes de distintas capturas apresentam grande dispersão em seu conteúdo de N-BVT, o que é atribuído a diferenças na condição biológica, alimentação, temperatura da água entre outras. Para o pescado de uma maneira geral, a literatura indica

Tabela 3. Características de frescor da matéria-prima e da polpa de anchoíta.

\begin{tabular}{lcc}
\hline \multicolumn{1}{c}{ Componentes } & $\begin{array}{c}\text { Matéria-prima } \\
\text { in natura* }\end{array}$ & Matéria-prima polpa \\
\hline $\mathrm{N}-\mathrm{BVT}\left(\mathrm{mg} \cdot 100 \mathrm{~g}^{-1}\right)$ & $11,5 \pm 0,10^{\mathrm{a}}$ & $20,2 \pm 0,11^{\mathrm{b}}$ \\
$\mathrm{N}-\mathrm{TMA}\left(\mathrm{mg} \cdot 100 \mathrm{~g}^{-1}\right)$ & $2,8 \pm 0,19^{\mathrm{a}}$ & $3,1 \pm 0,12^{\mathrm{b}}$ \\
$\mathrm{pH}$ & $6,3 \pm 0,04^{\mathrm{a}}$ & $6,7 \pm 0,03^{\mathrm{a}}$ \\
\hline${ }^{*}(\mu \pm \sigma)=$ valores médios de 6 repetições \pm desvio padrão; $\mathrm{p} \leq 0,05$; letras iguais na \\
mesma linha, não existe diferença significativa; letras diferentes na mesma linha, existe \\
diferença significativa.
\end{tabular}


valores entre 5 e $11 \mathrm{mg} .100 \mathrm{~g}^{-1}$ de músculo para excelente estado de frescor (CONTRERAS, 1994; CONTRERAS, 1988; GOULAS; KONTOMINAS, 2005; OGAWA; MAIA, 1999). Esta baixa concentração de N-BVT, que caracteriza o completo estado de frescor é atribuída à degradação do ATP (Adenosina Trifosfato), remanescente no pescado recém-morto. Supondo-se que todo o ATP seja degradado, seria obtido 7-12 mg N-BVT/100 g de músculo (CONTRERAS, 1988). Valores neste intervalo foram registrados para matéria-prima in natura nesta análise.

Denominam-se bases voláteis, o conjunto das bases nitrogenadas, como a TMA, DMA (dimetilamina), amônia, MMA (monometilamina), putrescina, cadaverina e espermidina, normalmente presentes em pescados que se deterioram, constituindo predominantemente uma mistura de amônia, TMA e DMA. Destas, o TMA é o que em geral tem variações mais significativas, portanto é a principal responsável pela mudança dos valores de N-BVT durante o armazenamento em gelo (BENJAKUL et al., 2005). De acordo com Connel (1990), citado por Goulas e Kontominas (2005), valores de N-TMA de 1,5 mg.100 g $\mathrm{g}^{-1}$ de músculo, têm sido indicados para bacalhau de ótima qualidade. Para o atum, estas concentrações variam de 1,5 a 2,0 mg.100 $\mathrm{g}^{-1}$ e, para carne de arenque e lagosta, o odor desagradável passa a ser percebido a partir de $7 \mathrm{mg} .100 \mathrm{~g}^{-1}$ (OGAWA; MAIA, 1999). Estas diferenças mostram que os níveis de TMA são dependentes das variações próprias das espécies, idade, estação do ano e dieta dos peixes (REDDY et al., 1997; RODRIGUEZ; BESTEIRO; PASCUAL, 1999). Logo os valores de $\mathrm{N}$-TMA registrados para o pescado in natura e para a polpa são aceitáveis, considerando-se que de acordo com Ogawa e Maia (1999) níveis de 4,0-6,0 mg.100 g ${ }^{-1}$ indicam baixa qualidade da matéria-prima, com detecção de odores desagradáveis.

Analisando-se a Tabela 3, verificam-se que são registrados maiores valores médios para N-BVT, pH e N-TMA para a polpa em relação à matéria-prima in natura. Garcia (2007) encontrou para a anchoíta recém-capturada valores de N-BVT e N-TMA de 8,22 e 0,92 mg. $100 \mathrm{~g}^{-1}$ de músculo, respectivamente. Comparando-se estes valores com os registrados para a polpa e matéria-prima in natura em análise, verificaram-se importantes diferenças. Além disso, neste trabalho foi observado que tanto para o N-BVT como para o N-TMA houve diferença significativa $(\alpha=5 \%)$ entre a matéria-prima in natura e a polpa de anchoíta. De acordo com Morais e Martins (1981) e Köse, Boran e Boran (2006), a deterioração da polpa ocorre de forma mais rápida do que a do pescado in natura, principalmente, devido à destruição da estrutura do músculo pelo processo de separação e pela inclusão na polpa de vários componentes indesejáveis, como sangue, fragmentos de espinhas e pela dispersão da flora microbiana presente na superfície da matéria-prima.

\subsection{Extração dos compostos nitrogenados da polpa de anchoíta}

O termo base proteica de pescado (BPP) se refere ao músculo de pescado lavado com água e misturado a substâncias crioprotetoras para evitar a desnaturação das proteínas musculares durante o congelamento (BENJAKUL et al., 2005; GONÇALVES; PASSOS, 2003; PARK, 2000). Na elaboração da $\mathrm{BPP}$, um dos processos mais importantes é a etapa de lavagem que, além de clarear a polpa, tem o objetivo de remover componentes naturais da carne do pescado que podem acelerar a deterioração (oxidação lipídica e microrganismos) durante a estocagem a baixa temperatura, como proteínas solúveis em água, sangue e outros componentes (GONÇALVES; PASSOS, 2003). A Tabela 4 apresenta os resultados obtidos para a extração de proteínas sarcoplasmáticas nos diferentes ciclos estudados.

Verifica-se que as maiores eficiências de extração ocorrem para as menores concentrações de $\mathrm{NaHCO}_{3}$, e se observou que entre os ciclos de lavagens $\mathrm{A}$ e $\mathrm{B}$ não ocorreu diferença significativa $(\alpha=5 \%)$; porém estes diferiram significativamente dos ciclos C e D. As proteínas sarcoplasmáticas extraídas representam entre 23 e $22 \%$ da proteína total do pescado in natura (Tabela 4). Estes resultados estão próximos aos obtidos por Simões et al. (2004), quando trabalharam com polpa de pescada-foguete (Macrodon ancylodon) lavada com água, assim como os resultados evidenciados por Maldonado (1994) para polpa de sardinha, utilizando água como solução de lavagem e uma solução equimolecular de cloreto de sódio $(\mathrm{NaCl})$ e bicarbonato de sódio 0,025 M. Além disso, sabe-se que, quando ocorre remoção de proteínas sarcoplasmáticas, há uma concentração de proteína miofibrilares, que são as principais responsáveis pela formação de gel.

A Tabela 5 registra as concentrações de nitrogenados como NT, NNP e NP, para cada tratamento utilizado no processo de lavagem.

Segundo Lanier (2000), os materiais solúveis em água são proteínas solúveis, enzimas hidrolíticas (principalmente proteases), sais inorgânicos, proteínas de baixo peso molecular e aminas. Conforme a Tabela 5 , foi observada diferença significativa $(\alpha=5 \%)$ entre todos os ciclos estudados para

Tabela 4. Extração das proteínas sarcoplasmáticas para os diferentes ciclos de lavagens.

\begin{tabular}{ccc}
\hline $\begin{array}{c}\text { Ciclos de } \\
\text { lavagens }\end{array}$ & $\begin{array}{c}\text { Extração total de proteínas } \\
\text { sarcoplasmáticas }(\%)^{*}\end{array}$ & $\begin{array}{c}\text { Extração em relação ao } \\
\text { total de proteínas na } \\
\text { polpa }(\%)^{*}\end{array}$ \\
\hline A & $82,0 \pm 2,1^{\mathrm{a}}$ & $23,0 \pm 0,6^{\mathrm{a}}$ \\
B & $80,0 \pm 1,0^{\mathrm{a}}$ & $22,5 \pm 0,6^{\mathrm{a}}$ \\
C & $67,0 \pm 1,2^{\mathrm{b}}$ & $18,8 \pm 0,7^{\mathrm{b}}$ \\
D & $54,0 \pm 1,0^{\mathrm{c}}$ & $15,3 \pm 0,3^{\mathrm{c}}$ \\
\hline
\end{tabular}

${ }^{*}(\mu \pm \sigma)=$ valores médios de 6 repetições \pm desvio padrão; $p \leq 0,05$; letras iguais na mesma coluna, não existe diferença significativa; letras diferentes na mesma coluna, existe diferença significativa.

Tabela 5. Determinação de nitrogênio $\left(\mathrm{g} .100 \mathrm{~g}^{-1}\right)$ nos ciclo de lavagem.

\begin{tabular}{cccc}
\hline $\begin{array}{c}\text { Ciclos de } \\
\text { lavagem }\end{array}$ & $\mathrm{NT}\left(\mathrm{g} .100 \mathrm{~g}^{-1}\right)$ & $\mathrm{NNP}\left(\mathrm{g} \cdot 100 \mathrm{~g}^{-1}\right)$ & $\mathrm{NP}\left(\mathrm{g} .100 \mathrm{~g}^{-1}\right)$ \\
\hline A & $0,643^{\mathrm{a}}$ & $0,185^{\mathrm{a}}$ & $0,457^{\mathrm{a}}$ \\
$\mathrm{B}$ & $0,557^{\mathrm{b}}$ & $0,093^{\mathrm{b}}$ & $0,463^{\mathrm{b}}$ \\
C & $0,440^{\mathrm{c}}$ & $0,110^{\mathrm{c}}$ & $0,330^{\mathrm{c}}$ \\
D & $0,436^{\mathrm{c}}$ & $0,088^{\mathrm{d}}$ & $0,347^{\mathrm{d}}$ \\
\hline
\end{tabular}

$\mathrm{p} \leq 0,05$; letras iguais na mesma coluna, não existe diferença significativa; letras diferentes na mesma coluna, existe diferença significativa. 
NNP e NP, porém para o NT não houve diferença significativa entre os ciclos C e D. Considerando-se que o teor de NNP nos teleósteos é em média 0,3 g.100 g-1 (CONTRERAS, 1994), o ciclo que utilizou $\mathrm{NaHCO}_{3} 0,1 \%$ (A) foi notadamente o mais eficiente, visto que o percentual médio de extração foi de $61,6 \%$. De acordo com Ogawa e Maia (1999), torna-se importante a remoção destes compostos, pois são responsáveis pelo odor a pescado e também aceleram a desnaturação proteica durante $\mathrm{o}$ armazenamento.

Segundo Ordóñez (2005), quando se utiliza na primeira lavagem do ciclo na polpa de pescado um reagente alcalino, este é utilizado para neutralizar o $\mathrm{pH}$ do músculo. A água fria é empregada para remover sujidades e lipídios e a baixa temperatura contribui para a não proliferação de microrganismos. De acordo com Montejano, Morales e Diaz (1993) e Ordóñez (2005), o NaCl no último ciclo de lavagem tem sido estudado no sentido de alterar a força iônica e facilitar a remoção final de água e, desta maneira, obter umidade similar ao músculo do pescado.

$\mathrm{Na}$ Tabela 6 pode-se observar os valores de $\mathrm{pH}$ das polpas de anchoíta medidos após cada lavagem.

Na Tabela 6 observa-se que ao final de cada ciclo houve diferença significativa $(\alpha=5 \%)$ entre os valores de $\mathrm{pH}$ das polpas. Verifica-se que o ciclo A apresentou menor variação de $\mathrm{pH}$ após cada lavagem e valores mais próximos da neutralidade. Segundo Ordóñez (2005), valores de $\mathrm{pH}$ em torno de 7 são importantes para a capacidade de formação de gel, pois as espécies pelágicas contêm grande quantidade de glicogênio depois da morte, sofrem decréscimos de $\mathrm{pH}$ (5,7 a 6), o que afeta intensamente as propriedades funcionais das proteínas miofibrilares.

Tabela 6. Valores de pH das polpas de anchoíta após cada lavagem.

\begin{tabular}{|c|c|c|c|}
\hline & Ciclos de lavagem & $\mathrm{pH}$ & Desvio padrão \\
\hline \multirow[t]{5}{*}{ A } & $0,1 \% \mathrm{NaHCO}_{3}$ & 7,62 & $\pm 0,17$ \\
\hline & $1^{\circ} \mathrm{H}_{2} \mathrm{O}$ & 7,50 & \\
\hline & $2^{\circ} \mathrm{H}_{2} \mathrm{O}$ & 7,40 & \\
\hline & $0,3 \% \mathrm{NaCl}$ & 7,21 & \\
\hline & Média & 7,43 & \\
\hline \multirow[t]{5}{*}{ B } & $0,2 \% \mathrm{NaHCO}_{3}$ & 8,09 & $\pm 0,36$ \\
\hline & $1^{\circ} \mathrm{H}_{2} \mathrm{O}$ & 7,67 & \\
\hline & $2^{\circ} \mathrm{H}_{2} \mathrm{O}$ & 7,42 & \\
\hline & $0,3 \% \mathrm{NaCl}$ & 7,25 & \\
\hline & Média & 7,61 & \\
\hline \multirow[t]{5}{*}{$\mathrm{C}$} & $0,3 \% \mathrm{NaHCO}_{3}$ & 8,29 & $\pm 0,43$ \\
\hline & $1^{\circ} \mathrm{H}_{2} \mathrm{O}$ & 8,01 & \\
\hline & $2^{\circ} \mathrm{H}_{2} \mathrm{O}$ & 7,60 & \\
\hline & $0,3 \% \mathrm{NaCl}$ & 7,30 & \\
\hline & Média & 7,8 & \\
\hline \multirow[t]{6}{*}{$\mathrm{D}$} & $0,5 \% \mathrm{NaHCO}_{3}$ & 8,56 & $\pm 0,57$ \\
\hline & $1^{\circ} \mathrm{H}_{2} \mathrm{O}$ & 7,48 & \\
\hline & $2^{\circ} \mathrm{H}_{2} \mathrm{O}$ & 7,62 & \\
\hline & $0,3 \% \mathrm{NaCl}$ & 7,26 & \\
\hline & Média & 7,73 & \\
\hline & Polpa não lavada & 6,84 & \\
\hline
\end{tabular}

Após a morte do pescado, o $\mathrm{pH}$ do músculo tende a aproximar-se do ponto isoelétrico das proteínas $(\mathrm{pH} \approx 5,0)$, devido ao acúmulo de ácido lático no post-mortem, como consequência, boa parte da água que está ligada às proteínas miofibrilares é exsudada, com isso ocorre perda de atributos sensoriais como suculência, textura e cor (TOLDRÁ, 2003).

Além disso, verifica-se que quanto maior a concentração de bicarbonato de sódio, maior foi o $\mathrm{pH}$ final da polpa. Logo, produtos que possuem $\mathrm{pH}$ muito alto estão sujeitos a uma vida útil curta, devido ao ambiente propício para a proliferação de microrganismos (DZIEZAK, 1990; SCHNEE, 2004; TEICHER, 1999).

\section{Conclusões}

A partir dos resultados deste trabalho, a anchoíta pode ser classificada como uma espécie semigorda. No entanto sua composição varia com a estação do ano e o local de captura.

Tanto o pH como o N-BVT para o pescado in natura e para a polpa não ultrapassaram o valor indicado pela legislação brasileira e os valores de N-TMA registrados foram aceitáveis, sugerindo que a técnica de conservação utilizada a bordo foi eficiente.

$\mathrm{O} \mathrm{NaHCO}_{3}$ 0,1\% demonstrou eficiência na remoção de nitrogenados da polpa de pescado; o ciclo com as lavagens de $\mathrm{NaHCO}_{3} 0,1 \%$, dois ciclos de água destilada e $\mathrm{NaCl} 0,3 \%$ demonstrou maior eficiência na extração das proteínas sarcoplasmáticas e, além disso, apresentou menor variação de $\mathrm{pH}$ após cada lavagem e valores mais próximos da neutralidade.

Dessa maneira, a espécie em estudo pode ser considerada uma matéria-prima com um potencial para produção de polpa de pescado, contribuindo para o desenvolvimento de novos produtos.

\section{Agradecimentos}

À Fundação Universidade Federal do Rio Grande (FURG) e ao CNPq.

\section{Referências bibliográficas}

ASSOCIATION OF OFFICIAL ANALYTICAL CHEMISTS - AOAC. Official methods of analysis. $13 \mathrm{ed}$. Arlington, 2000.

BENJAKUL, S. et al. Effect of frozen storage on chemical and gelforming properties of fish commonly used for surimi production in Thailand. Food Hydrocolloids, v. 19, n. 2, p. 197-207, 2005.

BERTOLOTTI, M. I.; MANCA, E. Processamiento y comercializacion de la anchoita (Engraulis anchoita) del Mar Argentino. Revista de Investigación y Desarrollo Pesquero, n. 5, p. 224-246, 1986.

BRASIL. Ministério da Agricultura. Métodos analíticos oficiais para controle de produtos de origem animal e seus ingredientes. Brasília, 1981. (v. II, Métodos físico e químico).

BRESSAN, M. C. Processamento de pescado de água doce. In: FEIRA DA PEQUENA AGROINDÚSTRIA, 2, 2002, Serra Negra, São Paulo, 2002. Anais... p. 59-85.

CASTELLO, L.; CASTELLO, J. P. Anchovy stocks (Engraulis anchoita) and larval growth in the SW Atlantic. Fisheries Research, v. 59, n. 3, p. 409-421, 2003. 
CASTELLO, J. P. A anchoita (Engraulis anchoita, Engraulididae, Pisces) no sul do Brasil. Rio Grande, 1997. Tese (Doutorado em Oceanografia Biológica) - Fundação Universidade Federal do Rio Grande - FURG.

CONTRERAS, E. Bioquímica de pescados e derivados. Jaboticabal: FUNEP, 1994.

CONTRERAS-GUZMÁN, E. S. Métodos químicos para análise do pescado. In: KAI, M.; RUIVO, U. E. Controle de qualidade do pescado. Santos: Leopoldianum, 1988. p. 196-209.

DZIEZAK, J. D. Phosphates improve many foods. Food Technology, v. 44, n. 4, p. 80-92, 1990.

FOOD AND AGRICULTURE ORGANIZATION - FAO. Aquaculture development. Roma, 1997. 40 p. (FAO Technical Guidelines for Responsible Fisheries, n. 5).

FUSELLI, S. R. et al. Microbiology of the marination process used in anchovy (Engraulis anchoita) production. LWT-Food Science and Technology, v. 27, n. 3, p. 214-218, 1994.

GARCIA, L. V. Avaliação das propriedades funcionais da anchoita (Engraulis anchoita) e das modificações produzidas durante o armazenamento em gelo e água do mar e processamento. Rio Grande, 2007. 135 p. Dissertação (Mestrado em Engenharia e Ciência de Alimentos) - Fundação Universidade Federal do Rio Grande - FURG.

GONÇALVES, A. A.; PASSOS, M. G. Uso da enzima transglutaminase na elaboração de um produto reestruturado à base de peixe. Revista Nacional da Carne, n. 317, p. 252-256, 2003.

GOULAS, A. E.; KONTOMINAS, M. G. Effect of salting and smokingmethod on the keeping quality of chub mackerel (Scomber japonicus): biochemical and sensory attributes. Food Chemistry, v. 93, n. 3, p. 511-520, 2005.

KÖSE, S.; BORAN, M.; BORAN, G. Storage properties of refrigerated whiting mince after mincing by three different methods. Food Chemistry, v. 99, n. 1, p. 129-135, 2006.

LANIER, T. C. Surimi technology. New York: Marcel Decker, 2000.

LUZIA, L. A. et al. The influence of season on the lipid profiles of five commercially important species of Brazilian fish. Food Chemistry, n. 83, p. 93-97, 2003.

MADUREIRA, L. S. P. et al. Component 4: Use of wild fish and/or other aquatic species to feed. Case study: South American anchovy, (Engraulis anchoita). In: Food and Agricultural Organization of the United Nations. (Org.). FAO Fisheries Technical Paper: Towards Sustainable Aquaculture: Selected Issues and Guidelines. 1 ed. Rome: FAO Fish Utilization and Marketing Service, 2007, v. 466, p. 1-29.

MAIA, E. L. et al. Composição química e classes de lipídios em peixe de água doce curimatã comum (Prochilodus cerensis). Ciência e Tecnologia de Alimentos, v. 19, n. 3, 1999.

MALDONADO, A. S. Efecto de la fuerza iônica em la extracción de proteínas sarcoplasmáticas em procesamiento de surimi. Boletin de Investigacion Instituto Tecnológico Pesquero del Peru, v. 4, n. 1, p. 9-14, 1994.

MARTIN, R. E. Chemistry and biochemistry of marine food products. Westport: AVI Publishing Company, 1982.
MATTOS, A. S. et al. Study on the utilization of Engraulis anchoita for the preparation of anchovies. In: International Conference on the Handling, Processing and Marketing of Tropical Fish, 1977, London.

MONTEJANO, J. G.; MORALES, O. G.; DIAZ, R. Evaluacion reologica de mezclas de surimi de dos espécies del Golfo de México. Ciência e Tecnologia de Alimentos, v. 13, n. 1, p. 35-44, 1993.

MORAIS, C.; MARTINS, J. F. P. Considerações sobre e o aproveitamento de sobras da industrialização de pescado na elaboração de produtos alimentícios. Boletim do Instituto de Tecnologia de Alimentos, v. 18, n. 3, p. 253-281, 1981.

OGAWA, M.; MAIA, E. L. Manual de pesca. São Paulo: Livraria Varela, 1999.

ORDÓÑEZ, J. A. Tecnologia de alimentos: alimentos de origem animal. Porto Alegre: Artmed, 2005. (v. 2.).

PANEK, A. D.; MARTELLI, H. L. Bioquímica experimental. Rio de Janeiro: Editora Ao Livro Técnico S. A, 1968.

PARK, J. W. Surimi and surimi seafood. New York: Marcel Dekker, 2000.

PARMIGIANI, P.; TORRES, R. A. Caminho da elite do agronegócio. Revista Aqüicultura e Pesca, Edição: 10, n. 34, p. 26-34, 2005.

REDDY, N. R. et al. Shelf life and clostridium botulinum toxin development during storage of modified atmosphere-packed fresh catfish fillets. Journal of Food Science, v. 62, n. 4, p. 878-884, 1997.

RODRIGUEZ, C. J.; BESTEIRO, I.; PASCUAL, C. Biochemical changes in freshwater rainbow trout (Oncorhynchus mykiss) during chilled storage. Journal of the Science of Food and Agriculture, v. 79, n. 11, p. 1473-1480, 1999.

SCHNEE, R. Budenheim phosphates for seafood processing. Alemanha: Chemische Fabrik Budenheim, 2004. 11 p.

SCHWINGEL, P. R.; CASTELLO, J. P. Programa para desenvolvimento da pescaria da anchoita (Engraulis anchoita) no sul do Brasil. Itajaí: Universidade do Vale do Itajaí, 2000. (Relatório final).

SIMÕES, D. R. S. et al. Desodorización de la Base Protéica de Pescado (BPP) con ácido fosfórico. Ciência e Tecnologia de Alimentos, v. 24, n. 1, p. 23-26, 2004.

TEICHER, H. Aplicação de fosfatos em carnes, aves e produtos marinhos. Revista Aditivos e Ingredientes, n. 5, p. 37-40, 1999.

THIANSILAKUL, Y.; BENJAKUL, S.; SHAHIDI, F. Compositions, functional properties and antioxidative activity of protein hydrolysates prepared from round scad (Decapterus maruadsi). Food Chemistry, v. 103, n. 4, p. 1-10, 2007.

TOLDRÁ, F. Muscle foods: water, structure and functionality. Food Science Technology International, v. 9, n. 3, p. 173-177, 2003.

TRONDSEN, T. et al. Perceived barriers to consumption of fish among Norwegian women. Research Report, n. 48, p. 301-314, 2003.

YEANNES, M. I.; ALMANDOS, M. E. Estimation of fish proximate composition starting from water conten. Journal of Food Composition and Analysis, v. 16, n. 1, p. 81-92, 2003.

YEANNES, M. I.; VALLE, C. E.; LUPÍN, H. M. Generación de bases nitrogenadas volátiles durante el processo de elaboración de conservas de pescado. Revista Agroquímica de Tecnologia de Alimentos, v. 23, n. 4, p. 585-590, 1983. 